\title{
Industry 4.0 Application in Lean Manufacturing- A Systematic Review
}

\author{
Sameh M. SAAD ${ }^{\mathrm{a}, 1}$, Chandan BHOVAR ${ }^{\mathrm{a}}$, Ramin BAHADORI ${ }^{\mathrm{a}}$ and Hongwei \\ ZHANG $^{\mathrm{a}}$ \\ ${ }^{a}$ Department of Engineering and Mathematics, Sheffield Hallam University \\ Sheffield S1 $1 \mathrm{WB}, \mathrm{UK}$
}

\begin{abstract}
For several years Lean manufacturing has been adopted by industries in improving the operational performance of the firm. However, Lean manufacturing is associated with fixed production sequence and slow responsiveness, which limits its capability of meeting the constantly changing customer demand, product variability \& customisation. This can inhibit its adaptability in the digital era. Meanwhile, Industry 4.0 technologies support the mass production of highly customisable products by being modular and flexible. Although Industry 4.0 technologies can meet the demands of the digital era, they are considered as a solution provider with little scope for organisational process improvement. Hence, an integration of both approaches will lead to a competitive advantage in the digital era. This paper aims to explore and evaluate the work done by researchers in identifying the link between lean manufacturing and Industry 4.0 technologies, through a systematic literature review to understand if lean manufacturing and Industry 4.0 technology can be integrated effectively.
\end{abstract}

Keywords. Lean Manufacturing, Industry 4.0., Systematic Review

\section{Introduction}

Today, manufacturing companies are facing diverse challenges which can be characterised as changing customer expectations, intense competition, globalisation, financial crisis, and economic downturn [1]. Under these challenging environments, companies need to adopt the most effective techniques and methodologies to stay competitive. Several such methodologies have been developed for companies to stay competitive such as Lean Manufacturing, Six Sigma, Lean Six Sigma, etc. Furthermore, for the organisation to be competitive, it must constantly adapt to the latest technologies and processes to maintain the sustainability of the process [2]. Industry 4.0 is the latest advancement in the industrial process, which is also termed as "fourth Industrial Revolution". It signifies a confluence of various technologies ranging from digital to material and process technologies. However, Industry 4.0 has been presented as a solution to ensure the productive sector success in the digital area, but with a little scope for organisational process improvement, such as those associated with Lean Manufacturing [3]. Lean Manufacturing developed during the third revolution is a management philosophy that focuses on improving the organisation's efficiency, implemented across different sectors of industries [4]. Lean Manufacturing is one such methodology that can significantly improve the quality, reduce cost, reduce lead time,

${ }^{1}$ Corresponding Author. S. Saad@shu.ac.uk 
and improve the productivity of the firm [5]. The widespread adaptability of Lean Manufacturing is due to the fact that it's easy to apply and provides effective results [6]. Although lean manufacturing is associated with fixed production sequence and slow responsiveness, against the changing customer expectation and product variability and customisation, Lean Manufacturing may not be able to meet the demands of the digital era, and its sustainability for the future can be limited [7]. So, one of the important aspects here is if Lean Manufacturing can be effectively integrated with Industry 4.0 to reap benefits from both digital technology advancement and organisational process improvement. Lean manufacturing and Industry 4.0 have similar goals, which correspond to improved quality, productivity, elimination of waste, and customeroriented [8]. Although there are similarities, it is interesting to note that lean manufacturing is associated with the empowerment of employees and is considered a Low-tech approach, contrary to the implementation of higher automation levels in Industry 4.0, which leads to a reduction of manpower. This paper aims at exploring the existing research on integrating Lean Manufacturing principles with Industry 4.0 technologies that have been published in academic journals by systematically reviewing the literature.

\section{Research Methodology}

This research work contributes to the systematic literature review (SLR) on the application of Industry 4.0 technologies in lean manufacturing in a manufacturing context. According to [9], SLR is a methodology that identifies the existing work done by researchers, selects and assesses the contribution from various researchers, analyses and synthesises the data, and produces the results in such a way that there is a clear summary of what is known and what is not. As shown in figure 1, this study follows

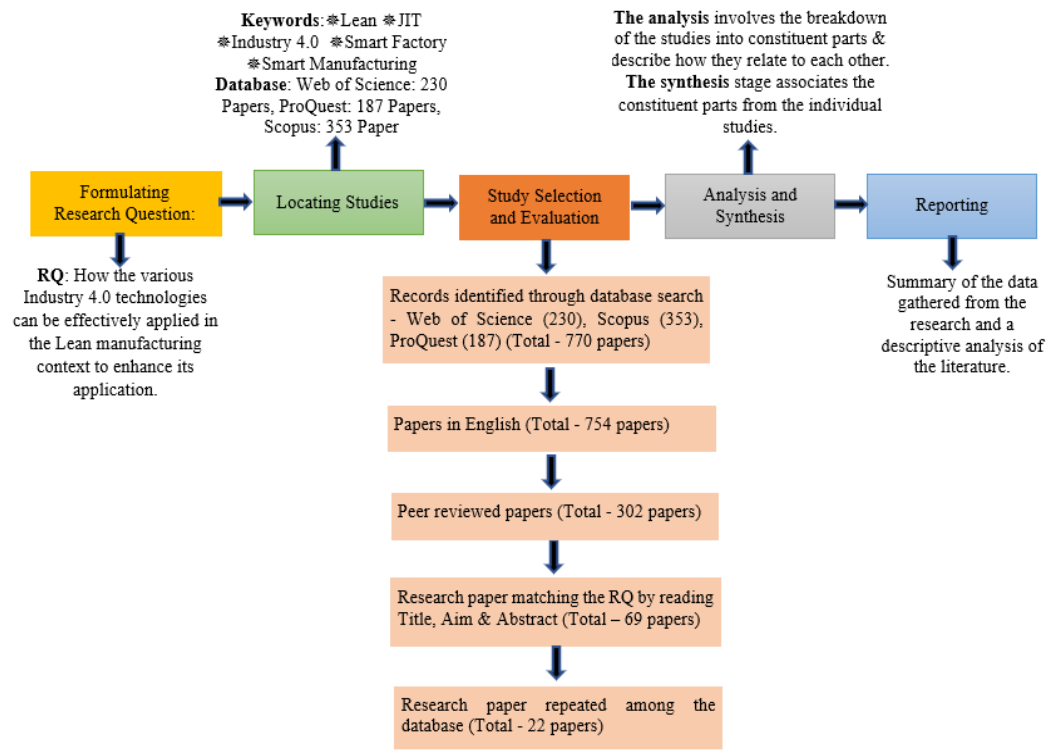

Figure 1: Research methodology 
a typical five SLR steps proposed by [9] consisting of 1) Question formulation; 2) Locating Studies; 3) Study selection and evaluation; 4) Analysis and Synthesis; 5) Reporting and using the results.

\section{Findings}

\subsection{Bibliometric Analysis}

In the 22 papers shortlisted, the first paper was published in the year 2016. Since then, there is a continuous rise in the number of publications depicting the interest of researchers and academicians in this area, with the highest publication of 13 in the year 2020 and five publications already in the first quarter of 2021. Concerning the contribution of Journals, the 'International Journal of Production research', 'Production planning and control' and 'Sensors' had two publications each, and all other journals have one publication each.

When the shortlisted papers were filtered from the country origin, Italy had the highest contribution with four papers, followed by Germany, UK, and Malaysia with three papers each. China had two papers and seven other countries had a contribution of one paper each. The contribution to the research from a developed country is $64 \%$ and from developing countries is $36 \%$. This signifies that even developing economies have shown tremendous interest in the field and have tried to adopt the latest technology. Globalisation has also contributed, as the companies from the developing economies have expanded globally with affiliate companies all over the world which has contributed to the development of the manufacturing sector in the developing countries.

On analysing the results of the research paper, nine industry 4.0 technologies were identified which were discussed by the authors in the research papers. The results depicted that IoT technology was the highest quoted by authors with 7 papers, CyberPhysical System appeared in four papers, Machine Learning and Cloud Computing appeared in three papers each, and remaining technologies were discussed in one paper each.

\subsection{Industry 4.0 tools supporting Lean Manufacturing}

IoT (Internet of Things) technologies such as RFID (Radio Frequency Identification) and LPWAN (Low Power Wide Area Network) are utilised to enhance digital traceability and to provide real-time information which can be effectively applied in Lean Manufacturing to identify and eliminate the waste [10-11]. IoT has also been used in integrating machines in the shop floor and also to connect to the machines with Andon systems to enhance the decision support system for process improvement [12-13]. IoT has also been applied to transform the traditional JIT (Just-In-Time) into dynamic JIT, which successfully addresses the challenges of traditional JIT by integrating modules integrated with IoT technologies into the Manufacturing Execution System (MES) [14]. IoT application is also shown to benefit the concept of SMED (Single Minute Exchange of Die), by providing embedded information to the product that can be directly communicated to the machine that requires a changeover, ensuring shorter changeover time through direct communication [15]. IoT has also shown effective synchronisation between the production and logistics by providing the logistic operator with real-time 
requirements and also proposes optimum travel routes to improve the process efficiency [16].

Machine learning (ML) is used to enhance the decision support system in JIT delivery performance by providing flexibility for the operator with re-scheduling options in case of production issues through the use of a human-machine interface [3]. ML contributes to the continuous improvement philosophy, in targeting specific performance indicators of complicated data-driven processes, by choosing the best improvement pathway under dynamic changes of production, which otherwise would have been a tedious task doing it manually [17]. ML also reduces the process lead time and has been effectively implemented in an additive manufacturing environment by accurately predicting the cooling time [18].

Cobots are also implemented effectively in the lean manufacturing environment. It promotes automation through careful gripper design to comply with safety norms to integrate the simultaneous operation of operator and robot [19].

Augmented Reality (AR) plays a vital role in ensuring Poka-Yoke or Jidoka systems. Kumar and Chiarini [20] quote examples from the survey where AR is used as Pokayoke and ensuring that the operator follows a standard operating procedure. In an instance, the operator has to tighten critical-to-safety bolts wearing smart 3D glasses. The glasses visualise a green light on picking the right critical bolt and facilitate the operator in choosing the right wrench. The glasses also ensure that the operator tightens the bolt with the right torque and will then carry out the next task. This example depicts the effective combination of the Industry 4.0 tool with the Lean principle giving optimum results.

Virtual Reality (VR) has been used to create a digital twin of the manufacturing process before the actual installation. It allows the manufacturing team to confirm the virtual world's design and ensure rectification of the problems before the installation [21]. This integration of VR in the confirmation process ensures a reduction in the rework and reduces the lead time of the project by ensuring fewer problems after installation.

Artificial Intelligence (AI) with the use of electroencephalography sensors is utilised to characterise and discerning between various types of behaviour. This practice is carried out on a balanced scorecard and hoshin kanri tree and conveys the unique characteristics observed by the process operator and the leader [22]. These devices are effective in imparting the training of the lean principles on the shopfloor and valuable feedback can be given by differentiating the systems and better understanding the thinking patterns.

Cyber-Physical Systems (CPS) are used to create real-time scheduling and dispatching system that runs on dynamic value stream map. It can monitor the flow of the products and spot the discrepancy between the physical and virtual world caused by Lean waste [23]. CPS is also deployed by integrating with pull production strategy to reduce the cost involved in the implementation by striking a balance between the extent of CPS implementation and the performance through an appropriate pull control strategy [24]. CPS is also used in implementing the Jidoka system in determining the optimum time for the tool wear in a CNC process and also initiate automatic tool change by reducing the need for the operator to perform the repetitive task [25].

Cloud Computing (CC) is implemented in dashboard-type monitoring of the process, enabling managers to make effective decisions [26]. CC along with RFID is used to grasp the real-time production records of production operators and the production equipment's for a labour-intensive production company [27]. CC is integrated with ERP (Enterprise Resource Planning) system to create a cloud ERP system that supports electronic Kanban, 
real-time monitoring of production volumes promoting JIT, FMEA (Failure mode effect analysis) of process, and supports preventive maintenance, spare part management, and tracking machine breakdown history [28].

Big Data Analytics (BDA) is effectively integrated with various guidelines of value stream map (VSM) to enhance and benefit the VSM design. It enables real-time takt definition, effective decision making in selecting finished goods strategy. BDA can successfully permit the re-dimensioning of supermarket policies and along with remote production process management would allow instant updates regarding fluctuations and variations which can halt interval achievement [29].

\section{Conclusion}

This research work contributes to the systematic literature review on the relation between Lean Manufacturing and Industry 4.0 technologies in a manufacturing context. As Industry 4.0 is associated with a list of technologies and is not a definitive set of technologies, nine technologies have been identified which were prominent in the research field. These Industry 4.0 technologies were then linked with different Lean Manufacturing principles and tools through the literature review and have been described in the main findings. It is also observed that Industry 4.0 technology has enhanced lean manufacturing tools through technology advancement, digitalisation and the use of the internet. The Industry 4.0 technology also has specifically improved on the challenges faced by traditional Lean tools and the combined effect has proven to provide the potential for the organisation to tackle the challenges of the digital era.

A bibliometric analysis of the literature review results also brings many insights into the research. The prominent insight derived is that the research area is a young research area with an increasing trend of interest from researchers and academicians in the field. Interestingly, Italy dominated with the maximum research papers in the field followed by Germany, UK, and Malaysia. This can be attributed to the search string keywords which were broadly focused on 'Lean manufacturing', 'Industry 4.0', and 'Manufacturing' sector.

This research by depicting the application of the Industry 4.0 technologies in Lean Manufacturing through systematic literature review methodology provides a foundation that can inspire further research efforts. Due to space limitation, the discovered future roadmap in this area will be presented at the conference.

\section{References}

[1] E. Psomas and J. Antony, Research gaps in Lean manufacturing: a systematic literature review, The International Journal of quality \& reliability management 36(5) (2019), 815-839.

[2] A.-Y. Chang and Y.-T. Cheng, Analysis model of the sustainability development of manufacturing small and medium- sized enterprises in Taiwan, Journal of cleaner production 207 (2019), 458-473.

[3] F. Yao, B. Alkan, B. Ahmad, and R. Harrison, Improving Just-in-Time Delivery Performance of IoTEnabled Flexible Manufacturing Systems with AGV Based Material Transportation, Sensors (Basel, Switzerland) 20(21) (2020), 6333.

[4] M. Sagnak, E. Ada, and Y. Kazancoglu, A new holistic conceptual framework for layout performance assessment, Journal of manufacturing technology management 30 (1) (2019), 233-260.

[5] A. Martnez Snchez and M. Prez Prezi, Lean indicators and manufacturing strategies, International Journal of operations \& production management 21 (11) (2001), 1433-1452.

[6] D. F. Simpson and D. J. Power, Use the supply relationship to develop lean and green suppliers, Supply chain management 10 (1) (2005), 60-68. 
[7] A. Mayr et al., Lean 4.0 - A conceptual conjunction of lean management and Industry 4.0, Procedia CIRP 72 (2018), 622-628.

[8] S.-V. Buer, J. O. Strandhagen, and F. T. S. Chan, The link between Industry 4.0 and lean manufacturing: mapping current research and establishing a research agenda, International Journal of production research 56 (8) (2018), 2924-2940.

[9] D. Denyer, and D. Tranfield, Producing a Systematic Review. The Sage Handbook of Organizational Research Methods. London: Sage Publications (2009), 671-689.

[10] M. J. Beliatis, K. Jensen, L. Ellegaard, A. Aagaard, and M. Presser, Next Generation Industrial IoT Digitalization for Traceability in Metal Manufacturing Industry: A Case Study of Industry 4.0, Electronics (Basel)10 (5) (2021), 628.

[11] A. M. Abed, S. Elattar, T. S. Gaafar, and F. M. Alrowais, The Neural Network Revamping the Process's Reliability in Deep Lean via Internet of Things, Processes 8 (6) (2020), 729.

[12] MS. Abd Rahman, E. Mohamad, AA. Abdul Rahman, Development of IoT - enabled data analytics enhance decision support system for lean manufacturing process improvement, Concurrent Engineering (2021), Lancaster, PA : Technomic Pub Co.

[13] T. Ito, MS. Abd Rahman, E. Mohamad, AA. Abd Rahman, MR. Salleh, Internet of things and simulation approach for decision support system in lean manufacturing. Journal of Advanced Mechanical Design, Systems, and Manufacturing 14(2) (2020), 19-00267.

[14] Y. Xu and M. Chen, An Internet of Things based framework to enhance just-in-time manufacturing, Proceedings of the Institution of Mechanical Engineers, Part B, Journal of engineering manufacture 232 (13) (2018), 2353-2363.

[15] A. Sanders, C. Elangeswaran, and J. Wulfsberg, Industry 4.0 implies lean manufacturing: Research activities in industry 4.0 function as enablers for lean manufacturing, Journal of industrial engineering and management 9 (3) (2016), 811-833.

[16] K. Zhang et al., IoT-enabled dynamic lean control mechanism for typical production systems, Journal of ambient intelligence and humanized computing 10 (3) (2019), 1009-1023.

[17] W. D. Leong et al., Enhancing the adaptability: Lean and green strategy towards the Industry Revolution 4.0, Journal of cleaner production 273 (2020), 122870.

[18] PV. Osswald et al., Optimization of the production processes of powder-based additive manufacturing technologies by means of a machine learning model for the temporal prognosis of the build and cooling phase, Production Engineering 14(5) (2020), 677-91.

[19] F. Rossi et al., Effective integration of Cobots and additive manufacturing for reconfigurable assembly solutions of biomedical products, International Journal on Interactive Design and Manufacturing (IJIDeM) 14(3) (2020), 1085-9.

[20] A. Chiarini and M. Kumar, Lean Six Sigma and Industry 4.0 integration for Operational Excellence: evidence from Italian manufacturing companies, Production planning \& control (2020), 1-18.

[21] L. Pérez, S. Rodríguez-Jiménez, N. Rodríguez, R. Usamentiaga, and D. F. García, Digital Twin and Virtual Reality Based Methodology for Multi-Robot Manufacturing Cell Commissioning, Applied sciences 10 (10) (2020), 3633 .

[22] D. Schmidt, J. Villalba Diez, J. Ordieres-Meré, R. Gevers, J. Schwiep, and M. Molina, Industry 4.0 Lean Shopfloor Management Characterization Using EEG Sensors and Deep Learning, Sensors (Basel, Switzerland) 20 (10) (2020), 2860.

[23] M. Ramadan, B. Salah, M. Othman, and A. A. Ayubali, Industry 4.0-Based Real-Time Scheduling and Dispatching in Lean Manufacturing Systems, Sustainability (Basel, Switzerland)12 (6) (2020), 2272.

[24] G. Huang, J. Chen, and Y. Khojasteh, A cyber-physical system deployment based on pull strategies for one-of-a-kind production with limited resources, Journal of intelligent manufacturing 32 (2) (2021), 579596.

[25] D. Romero, P. Gaiardelli, D. Powell, T. Wuest, and M. Thürer, Rethinking Jidoka Systems under Automation \& Learning Perspectives in the Digital Lean Manufacturing World, IFAC PapersOnLine 52(13) (2019) 899-903.

[26] M. Shahin, F. F. Chen, H. Bouzary, and K. Krishnaiyer, Integration of Lean practices and Industry 4.0 technologies: smart manufacturing for next-generation enterprises, International Journal of advanced manufacturing technology 107 (5-6) (2020), 2927-2936.

[27] Z. Guo, E. W. Ngai, C. Yang, and X. Liang, An RFID-based intelligent decision support system architecture for production monitoring and scheduling in a distributed manufacturing environment, International Journal of production economics 159 (2015), 16-28.

[28] M. Ghobakhloo, The future of manufacturing industry: a strategic roadmap toward Industry 4.0, Journal of manufacturing technology management 29 (6) (2018). 910-936.

[29] G. L. Tortorella et al., Designing lean value streams in the fourth industrial revolution era: proposition of technology-integrated guidelines, International Journal of production research 58 (16) (2020), 50205033 . 